\title{
Prescription and technological efficiency of sedimentary rocks of various composition and genesis in cement systems
}

\author{
Artemy S. Balykov* (iD, Tatyana A. Nizina (D), Vladimir M. Kyashkin (D), Sergey V. Volodin (iD \\ National Research Mordovia State University, Saransk, Russia \\ * Corresponding author: e-mail: artbalrun@yandex.ru
}

\begin{abstract}
Introduction. Active mineral additives that allow controlling the structure formation processes and properties of cement systems are important components of modern modified concretes. Among the numerous types of modifiers for cement composites, the most effective ones include siliceous and aluminosilicate additives containing a significant amount of nanoscale particles, in particular, nanoparticles of silicon dioxides, clays, aluminum oxides and iron oxides. At the same time, common sedimentary rocks, such as diatomites, trepels, opokas, polymineral clays, etc., along with industrial wastes (silica fumes, fly ashes, metallurgical slags) can be promising raw materials for obtaining such modifiers. The purpose of this study was to establish the influence regularities of mineral additives based on sedimentary rocks of various composition and genesis on the technological and physico-mechanical properties of cement systems with the identification of the most effective modifiers. Methods and materials. Siliceous rocks (diatomite and opoka), calcined polymineral clays and carbonate rocks (dolomite and chalk) from several deposits of the Republic of Mordovia were used as mineral additives. The study of the chemical and mineralogical composition of sedimentary rocks was carried out using X-ray spectral fluorescence spectrometry and X-ray powder diffraction methods. In addition to the chemical and mineralogical composition, at the initial stage of the study, the specific surface area of mineral additives and Portland cement was determined on the PSX-12 dispersion analysis device using the Kozeny-Carman method. Prescription and technological efficiency of the applied mineral modifiers was evaluated by their effect on water demand, water-holding capacity, flowability of cement paste and mixed cement binder activity. The physical and mechanical characteristics of cement systems were determined using standardized and well-known authorial methods. Results and discussion. There were established correlation dependences between indicators of water demand, water-holding capacity, flowability of cement systems and specific surface of mineral additives used. In addition, relationship between the activity index of the studied modifiers and the content of silicon dioxide in their composition was revealed. Conclusions. According to the totality of the conducted studies, diatomite, opoka and calcined polymineral clay were identified as the most promising types of mineral additives. The increased effectiveness of these modifiers in cement systems is due to the peculiarities of their chemical and mineralogical composition, in particular, the presence of active silica-containing components (reactive minerals with an amorphized structure) such as opal-cristobalite-tridymite phase in diatomite and opoka as well as products of partial thermal destruction (dehydroxylation) of minerals of kaolinite and illite groups in the calcined polymineral clay.
\end{abstract}

KEYWORDS: cement system, nanomodifier, mineral additive, sedimentary rock, nanoparticle, chemical and mineralogical composition, physical and mechanical properties, prescription and technological efficiency.

ACKNOWLEDGMENTS: The research was supported by grant from the Russian Science Foundation (project No. 21-73-00228), https://rscf.ru/en/project/21-73-00228/.

FOR CITATION: Balykov A.S., Nizina T.A., Kyashkin V.M., Volodin S.V. Prescription and technological efficiency of sedimentary rocks of various composition and genesis in cement systems. Nanotechnologies in Construction. 2022; 14(1): 53-61. https://doi. org/10.15828/2075-8545-2022-14-1-53-61.

\section{INTRODUCTION}

$\mathrm{C}$ urrently, one of the priority areas of building materials science is the development of theoretical and technological foundations for the design and synthesis of high performance cement system structures at vari- ous scale levels such as macro, meso, micro levels, up to understanding the importance of the nanoscale level of the material structure organization. Structural modification of the cement matrix through the use of micro or nanoparticles and fibers provides a largely high level of properties of such composites [1, 2, 3, 4].

(c) Balykov A.S., Nizina T.A., Kyashkin V.M., Volodin S.V., 2022 
Among the numerous types of cement system nanomodifiers, the most effective ones include:

- silicon dioxide $\left(\mathrm{SiO}_{2}\right)$ nanoparticles with a high specific surface area (at least $180 \mathrm{~m}^{2} / \mathrm{g}$ ), contributing to the achievement of radically new physical and mechanical characteristics of cement stone (strength, creep, shrinkage, etc.) due to reduced structure porosity and improved stacking of the structure components, and also thanks to directional changing in the solid phase quality, that it consist in replacing Portlandite crystals and high basic calcium hydrosilicates of C-S-H(II) type with low basic C-S-H(I) phases responsible for the strength and durability of cement composites $[5,6]$;

- nanoparticles of clays (aluminosilicates), aluminum oxides $\left(\mathrm{Al}_{2} \mathrm{O}_{3}\right)$ and iron oxides $\left(\mathrm{Fe}_{2} \mathrm{O}_{3}\right)$ that improve elasticity modulus and strength characteristics of cement stone, reduce shrinkage composite deformations and their structure permeability for chlorides, and also make it possible to monitor and record their own compressive stresses of cement systems through change assessment in the volumetric electrical resistance of solutions with these nanoparticles [7, 8].

In addition to using nanomodifiers, the development of physico-chemical and technological methods for controlling the structure parametrs of cement composites at the microscale level remains an important issue. The increased efficiency of using highly dispersive siliceous and aluminosilicate additives of natural and technogenic origin, such as silica fumes, metakaolins, fly ashes, metallurgical slags, etc., in the cement system compositions was established based on the numerous research results by Russian and foreign authors $[9,10,11,12,13]$, including their own $[14,15]$. These mineral additives can have a noticeable amount of nanoscale particles, although basically their granulometric composition is in the micrometric range $\left(10^{-5}-10^{-7} \mathrm{~m}\right)$.

At the same time, it is worth noting that the territorial limitation, composition variability and often the high cost of the above additives are the main constraining factors of their use. In this regard, expanding the raw material base for obtaining effective mineral additives based on available natural raw materials is an important task. One of the most promising in this respect for many regions of the Russian Federation are common raw materials such as siliceous opal-cristobalite rocks $[16,17$, $18]$, polymineral clays $[19,20,21]$ and carbonate rocks $[22,23,24]$.

The purpose of this study was to establish the influence regularities of mineral additives (MA) based on sedimentary rocks of different composition and genesis (siliceous, clay and carbonate rocks) on the technological and physico-mechanical properties of cement systems with the identification of the most effective modifiers.
To achieve this objective, the following tasks were solved:

- the chemical and mineralogical composition was studied for the initial sedimentary rocks;

- the effects of mineral additives based on sedimentary rocks of different composition on the water demand, water-holding capacity and flowability of the cement paste were researched;

- the influence of mineral modifiers on the mixed cement binder activity was studied;

- the most effective sedimentary rocks have been established which make it possible to directionally control the technological and physical-mechanical properties of cement systems.

\section{METHODS AND MATERIALS}

\section{Materials}

The main component of binder in the cement system recipes was Portland cement 500-D0-N (PC) produced by Mordovcement PJSC.

Several groups of sedimentary rocks, previously crushed to different specific surface area, were used as mineral additives:

1) siliceous opal-cristobalite rocks such as diatomite from the Atemarsky deposit of the Republic of Mordovia (DTMT1, DTMT2 and DTMT3); opoka from the Alekseevsky deposit of the Republic of Mordovia (OPK1 and OPK2);

2) clay rocks such as calcined polymineral clays from the Nikitsky (CCN) and Staroshaigovsky (CCS) deposits of the Republic of Mordovia;

\section{Table 1}

The types of mineral additives used in the cement system compositions and the values of their specific surface area

\begin{tabular}{|c|c|c|}
\hline $\begin{array}{c}\text { Composition } \\
\text { number }\end{array}$ & $\begin{array}{c}\text { Type of mineral } \\
\text { additives }\end{array}$ & $\begin{array}{c}\text { Specific surface } \\
\text { area of } \mathbf{M A}, \mathbf{~ m}^{2} \mathbf{~ g}\end{array}$ \\
\hline 1 & - & - \\
\hline 2 & DTMT1 & 2.40 \\
\hline 3 & DTMT2 & 2.45 \\
\hline 4 & DTMT3 & 2.85 \\
\hline 5 & OPK1 & 0.70 \\
\hline 6 & OPK2 & 0.80 \\
\hline 7 & CCN & 0.78 \\
\hline 8 & CCS & 0.52 \\
\hline 9 & DY & 0.45 \\
\hline 10 & CA & 1.30 \\
\hline
\end{tabular}

Note: the specific surface area of Portland cement used in the experimental study was $0.32 \mathrm{~m}^{2} / \mathrm{g}$. 
3) carbonate rocks such as dolomite from the Yelnikovsky deposit (DY) and chalk of the Atemarsky deposit (CA) of the Republic of Mordovia.

The types of mineral additives used in the cement system compositions, together with the values of their specific surface area, are shown in Table 1.

\section{Methods}

The specific surface area of the used mineral additives and Portland cement was determined on the dispersion analysis PSKh-12 device by the Kozeny-Carman method based on the air permeability and porosity establishment of the powder compacted layer. The gas permeability of the powder layer was measured according to the filtering duration of given air volume through the device at fixed vacuum in its working volume.

The research of the chemical composition of sedimentary rocks was carried out by X-ray fluorescence (XRF) spectrometry, based on the collection and subsequent analysis of the spectrum that occurs when the material under study is irradiated with X-ray radiation. The test equipment used was sequential $\mathrm{X}$-ray fluorescence wave spectrometer ARL Perform'X 4200 (Rh Ka radiation), designed for qualitative and quantitative analysis of the elemental composition of materials in the range of analyzed elements from $\mathrm{F}$ to $\mathrm{U}$. Based on the results of determining the elemental composition of samples, the established concentrations of individual chemical elements were recalculated to their oxides.

The phase composition analysis of sedimentary rocks was done using X-ray powder diffraction (XRD phase analysis). X-ray structural measurements were conducted using an Empyrean automated diffractometer by PANalytical (Netherlands) with a vertical goniometer in the radiation of a copper anode with a nickel filter ensuring suppression of the background and spectral line $\mathrm{K} \beta$ together with the monochromator on the secondary beam. Shooting was done in the geometry according to BraggBrentano $(\theta-2 \theta$ scanning) using a spectral doublet $\mathrm{Cu}$ K $\alpha 1,2$ with weighted average wavelength $\lambda=1.5406 \AA$. $\mathrm{X}$-ray powder diffraction patterns were obtained using PIXcel3D two-coordinate semiconductor detector operating in the linear detector mode.

In addition to the main crystalline phases, the crystallinity degree was determined for samples of siliceous opal-cristobalite rocks whose diffraction patterns contain an amorphous halo (diatomite, opoka). The crystallinity degree of these samples $(\alpha c)$ was calculated as the ratio of the integral scattering intensity of crystallites to the total intensity of the total scattering from amorphous and crystalline regions:

$$
\alpha_{c}=\left(I_{c} /\left(I_{c}+I_{a}\right)\right) \cdot 100 \%,
$$

where $I_{c}$ is the integrated intensity (total area) of all crystalline peaks; $I_{a}$ is the integral intensity of amorphous halo.

The intensities of crystalline peaks and amorphous halo on the diffraction patterns were calculated as areas under the corresponding curves.

Prescription and technological efficiency of the used mineral additives was evaluated by their influence on the following cement system indicators: water demand, waterholding capacity and flowability of cement paste as well as the activity of mixed cement binder. The research subjects were cement systems with total dosage of mineral additives equal to $10 \%$ by weight of the binder (PC+MA). The composition without mineral additives was adopted as a control composition.

The water demand of cement systems was estimated in the mixed binder system ( $90 \%$ of Portland cement and $10 \%$ of mineral additive) by water/solid (water/binder) ratio $(\mathrm{W} /(\mathrm{PC}+\mathrm{MA}))$ of cement paste corresponding to its normal density which was determined on the Vicat apparatus in accordance with the method of the Russian State Standard GOST 310.3.

The water-holding capacity of cement systems was determined by the water separation values of cement paste consisting of a mixed binder (90\% PC $+10 \% \mathrm{MA})$ and water $($ water-binder ratio $\mathrm{W} /(\mathrm{PC}+\mathrm{MA})=1)$, when settling the particles of the solid phase in a graduated cylinder in accordance with the Russian State Standard GOST 310.6. The volume of settled cement paste and water accumulated on its surface was recorded every 30 minutes after the first counting for 2 hours. The ratio of the volume of water accumulated on the surface of the paste to the initial volume of the suspension, expressed as a percentage (water separation coefficient by volume) was taken as the water separation value.

The influence regularities of mineral additives on the cement paste flowability were established in compositions with a constant water content (water-binder ratio) using the Hagermann cone (form-cone from the shaking table according to the Russian State Standard GOST 310.4).

The selection of mineral additives was carried out according to the results of the study of their effect on the activity of cement binder with the definition of the activity index of the modifier. The activity index of applied mineral additives was determined under the Russian State Standard GOST R 56178-2014 method by comparing the results of compression strength tests after steaming cement-sand samples-beams of $40 \times 40 \times 160$ $\mathrm{mm}$, made using of modified binders consisting of $90 \%$ Portland cement and $10 \%$ mineral additive (by weight of the binder (PC+MA)), and control samples of unmodified composition with a ratio of cement binder and standard monofractional sand equal to $1 /{ }^{\text {. }}$. The waterbinder ratio was taken the same for all compositions, it equated to the value established for the most water- 
demanding composition when the flow spread diameter of fine-grained concrete mixture from the Hagermann cone was reached of $106-108 \mathrm{~mm}$. The procedure for manufacturing and testing of samples-beams adopted following the requirements of the Russian State Standard GOST 310.4, the mode of heat and humidity treatment is selected following the Russian State Standard GOST R 56178-2014 equal to $(3+3+6+2)$ hours at isothermal holding temperature of $80^{\circ} \mathrm{C}$.

Based on the results of determining the compressive strength of steamed samples (the activity of cement binders), the activity index of applied mineral additives $\left(C_{M A}\right)$ was calculated using the formula

$$
C_{M A}=R_{2} / R_{1},
$$

where $R_{1}$ and $R_{2}$ are compressive strength of samples of unmodified (control) and modified (main) compositions, respectively, $\mathrm{MPa}$.

\section{RESULTS AND DISCUSSION}

\section{Chemical and mineralogical composition of the initial sedimentary rocks}

The chemical (oxide) composition of the studied siliceous rocks (Atemarsky diatomite and Alekseevsky opoka) as well as clays of the Nikitsky and Staroshaigovsky deposits is shown in Table 2.

Data analysis of data obtained by X-ray fluorescence spectrometry showed the predominance of silicon, aluminum, and iron oxides in the chemical composition of the studied siliceous and clay rocks (wt. \%): 53.19-87.23 $\left(\mathrm{SiO}_{2}\right) ; 5.15-15.78\left(\mathrm{Al}_{2} \mathrm{O}_{3}\right) ; 3.41-17.28\left(\mathrm{Fe}_{2} \mathrm{O}_{3}\right)$ (Table 2).

The diffraction patterns of the studied sedimentary rock powders are shown in the Figure 1.

The results of qualitative and quantitative XRD phase analysis to determine the main crystalline phases and their relative concentrations for clays of the Nikitsky and Staroshaigovsky deposits are given in Table 3. It has been found that the phase compositions of the studied clay rocks are represented (Fig. 1) predominantly by minerals of the kaolinite group $(d=[\ldots ; 7.16-7.19 ; \ldots ; 4.04-4.05 ; \ldots$; $3.57-3.58 ; \ldots ; 2.34-2.35 \AA ; \ldots], 2 \theta=[\ldots ; 12.3 ; \ldots ; 22.0$; $\left.\left.\ldots ; 24.9 ; \ldots ; 38.4^{\circ} ; \ldots\right]\right)$ and illite group (hydromicas) $(d=$ $[\ldots ; 10.02 ; \ldots ; 4.48-4.49 ; \ldots ; 3.79-3.80 ; \ldots ; 3.49-3.50$; $\ldots ; 3.35-3.36 ; \ldots ; 3.22-3.23 ; \ldots ; 3.00 ; \ldots ; 2.57 ; \ldots ; 1.50 \AA$ $\ldots], 2 \theta=[\ldots ; 8.8 ; \ldots ; 19.8 ; \ldots ; 23.5 \ldots ; 25.4 \ldots ; 26.6 ; \ldots$; $\left.\left.27.7 ; \ldots ; 29.8 ; \ldots ; 34.9 ; \ldots ; 61.6^{\circ} ; \ldots\right]\right)$ as well as by quartz modifications $(d=[\ldots ; 4.27 ; \ldots ; 3.35-3.36 ; \ldots ; 1.82 \AA$; $\left.\ldots], 2 \theta=\left[\ldots ; 20.8 ; \ldots ; 26.6 ; \ldots ; 50.1^{\circ} ; \ldots\right]\right)$, feldspars $(d=$ $[\ldots ; 4.04-4.05 ; \ldots ; 3.79-3.80 ; \ldots ; 3.26 ; \ldots ; 3.20-3.23$; $\ldots ; 2.94 ; \ldots ; 2.46 ; \ldots ; 2.29 ; \ldots ; 2.24 ; \ldots ; 2.13 ; \ldots ; 1.98 ; \ldots$; $1.67 ; \ldots ; 1.54 ; \ldots ; 1.38 \AA ; \ldots], 2 \theta=[\ldots ; 22.0 ; \ldots ; 23.4 ; \ldots$; $27.4 ; \ldots ; 27.7-27.9 ; \ldots ; 30.4 ; \ldots ; 36.5 ; \ldots ; 39.4 ; \ldots ; 40.2 ; \ldots$; $\left.\left.42.4 ; \ldots ; 45.7 ; \ldots ; 54.8 ; \ldots ; 59.9 ; \ldots ; 67.7^{\circ} ; \ldots\right]\right)$, and gyp$\operatorname{sum}(d=[\ldots ; 7.63 ; \ldots ; 4.27 ; \ldots ; 3.80 ; \ldots ; 3.07 ; \ldots ; 2.87 ; \ldots$; $2.69 \AA ; \ldots], 2 \theta=[\ldots ; 11.6 ; \ldots ; 20.8 ; \ldots ; 23.4 ; \ldots ; 29.0 ; \ldots$; $\left.\left.31.1 ; \ldots ; 33.3^{\circ} ; \ldots\right]\right)$ at their relative content in the overall mass of crystalline phases (wt. \%): 18.0-39.8; 23.1-23.2; $19.8-46.9 ; 11.9-14.2$ and $0-3.1$, respectively, i.e. the represented clays are polymineral.

The mineralogical compositions of siliceous rocks (diatomite and opoka) are represented (Fig. 1) predominantly by crystalline quartz $(d=[\ldots ; 4.27-4.30 ; \ldots ; 3.35-3.37 ; \ldots$; $1.82 \AA ; \ldots], 2 \theta=[\ldots ; 20.6-20.8 ; \ldots ; 26.4-26.6$; ...; 49.9$\left.\left.50.1^{\circ} ; \ldots\right]\right)$ and partially crystallized opal-cristobalite- tridymite phase (OCT phase) $\left(2 \theta=18-25^{\circ}\right)$ which is a mixture of crystalline and cryptocrystalline varieties of silica such as cristobalite, tridymite and X-ray amorphous opal. The variability of real structure and characteristic features of individual natural siliceous phases such as the type of complex diffraction profile, the broadening degree of main peak, the resolution and relative intensities of its components, and the migration of interplanar distance value are clearly manifested in the diffraction patterns.

The crystallinity degree of the studied mineral additive samples increases in the direction from diatomite to opoka (from 21.9 to $36.5 \%$ ) which was established from analysis of the diffraction patterns of siliceous rock powders. The high degree of material structure amorphization, the presence of active silica forms and the structural diversity of

\section{Table 2}

Chemical composition of the studied siliceous and clay rocks based on the XRF analysis results (converted to oxides)

\begin{tabular}{|c|c|c|c|c|c|c|c|c|c|c|c|c|c|c|c|c|}
\hline \multirow{2}{*}{ Sedimentary rock } & \multicolumn{16}{|c|}{ Oxides [wt. \%] } \\
\hline & $\mathrm{SiO}_{2}$ & $\mathrm{Al}_{2} \mathrm{O}_{3}$ & $\mathrm{Fe}_{2} \mathrm{O}_{3}$ & $\mathrm{~K}_{2} \mathrm{O}$ & $\mathrm{Na}_{2} \mathrm{O}$ & $\mathrm{CaO}$ & MgO & $\mathrm{TiO}_{2}$ & $\mathbf{P}_{2} \mathbf{O}_{5}$ & $\mathrm{ZrO}_{2}$ & MnO & $\mathrm{SO}_{3}$ & $\mathrm{WO}_{3}$ & $\mathrm{NiO}$ & $\mathrm{BaO}$ & other \\
\hline $\begin{array}{l}\text { Atemarsky } \\
\text { diatomite }\end{array}$ & 87.23 & 5.15 & 3.41 & 1.21 & - & 1.75 & 0.73 & 0.32 & 0.06 & - & - & 0.03 & - & - & - & 0.11 \\
\hline Alekseevsky opoka & 73.46 & 13.26 & 4.32 & \multicolumn{2}{|c|}{1.90} & \multicolumn{2}{|c|}{6.01} & 0.67 & 0.06 & - & - & 0.09 & - & - & - & 0.23 \\
\hline Nikitsky clay & 53.19 & 15.78 & 17.28 & 6.17 & 0.34 & 1.60 & 1.26 & 1.52 & 0.25 & - & - & 1.20 & 0.52 & 0.28 & - & 0.61 \\
\hline $\begin{array}{l}\text { Staroshaigovsky } \\
\text { clay }\end{array}$ & 66.12 & 13.72 & 10.90 & 4.32 & 0.55 & 1.68 & 1.12 & 0.64 & 0.26 & 0.18 & 0.13 & - & - & - & 0.07 & 0.31 \\
\hline
\end{tabular}




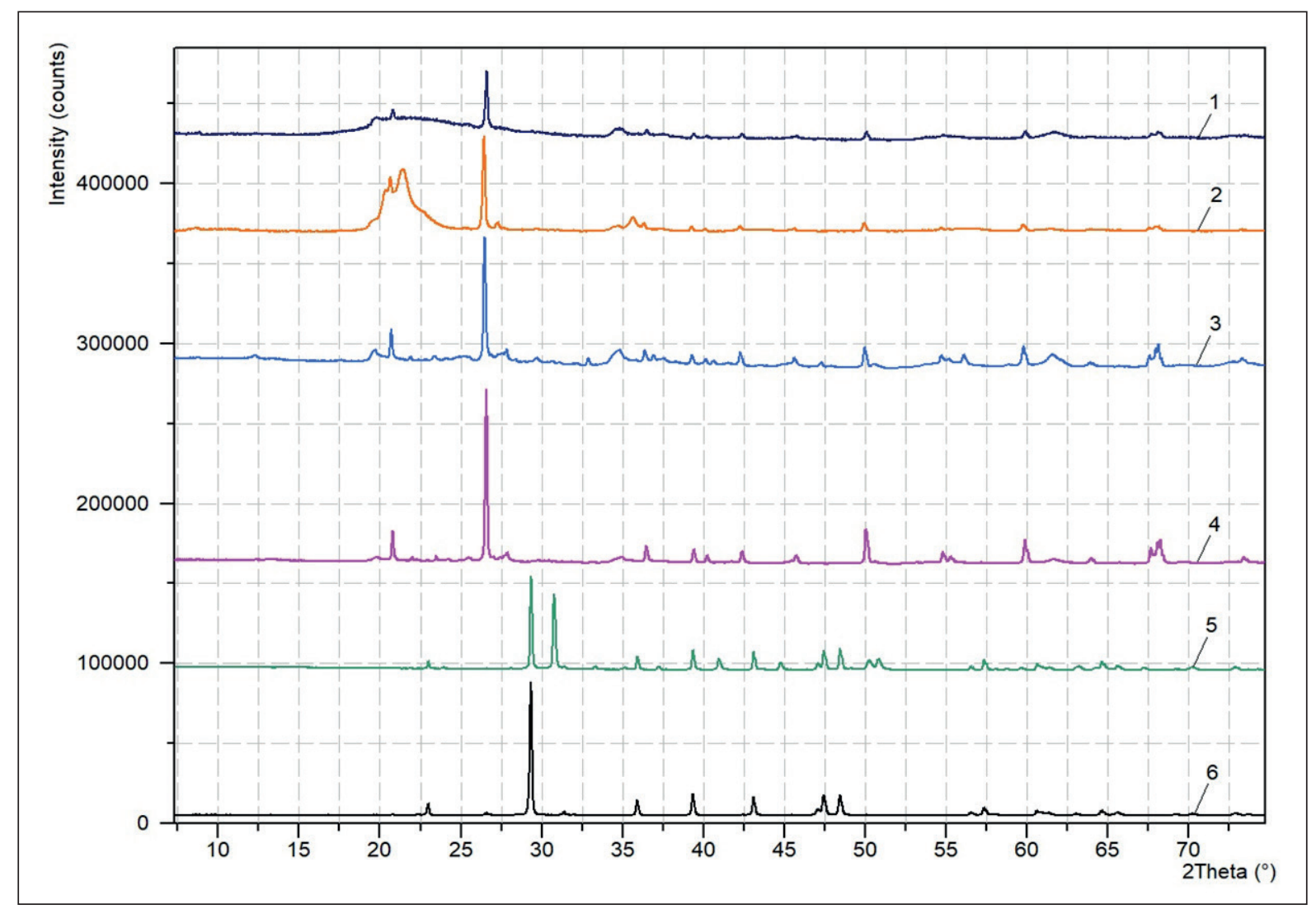

Fig. 1. Diffraction patterns of the studied sedimentary rock powders: Atemarsky diatomite (1); Alekseevsky opoka (2); Nikitsky clay (3); Staroshaigovsky clay (4); Yelnikovsky dolomite (5); Atemarsky chalk (6)

siliceous substance cause improved physical and chemical characteristics of diatomite and opoka, in particular their increased pozzolanic activity in cement systems.

The mineralogical composition of the Yelnikovsky dolomite is represented by phases of the dolomite $\mathrm{CaMg}\left(\mathrm{CO}_{3}\right)_{2}(d=[\ldots ; 2.90 ; \ldots ; 2.41 ; \ldots ; 2.20 ; \ldots ; 2.02$; $\ldots ; 1.82 ; \ldots ; 1.80 \AA ; \ldots], 2 \theta=[\ldots ; 30.8 ; \ldots ; 37.2 ; \ldots ; 41.0$; $\left.\left.\ldots ; 44.8 ; \ldots ; 50.2 ; \ldots ; 50.8^{\circ} ; \ldots\right]\right)$ and calcite $\mathrm{CaCO}_{3}(d=$ $[\ldots ; 3.87 ; \ldots ; 3.04 ; \ldots ; 2.50 ; \ldots ; 2.29 ; \ldots ; 2.10 ; \ldots ; 1.91 ; \ldots$; $1.88 \AA ; \ldots], 2 \theta=[\ldots ; 23.0 ; \ldots ; 29.3 ; \ldots ; 35.9 ; \ldots ; 39.4 ; \ldots$; $\left.\left.43.1 ; \ldots ; 47.4 ; \ldots ; 48.5^{\circ} ; \ldots\right]\right)$ with the relative phase contents of 52 wt. $\%$ and 48 wt. $\%$ for dolomite and calcite,

Table 3

Crystalline phase concentrations in the mineralogical compositions of the studied clays (before calcination)

\begin{tabular}{|l|c|c|c|c|c|}
\hline \multirow{2}{*}{ Deposit } & \multicolumn{5}{|c|}{ Crystalline phases [wt. \%] } \\
\cline { 2 - 6 } & Kaolinite & $\begin{array}{c}\text { Illite group } \\
\text { (hydromicas) }\end{array}$ & $\begin{array}{c}\text { Quartz } \\
\text { modifications }\end{array}$ & Feldspars & Gypsum \\
\hline Nikitsky & 39.8 & 23.1 & 19.8 & 14.2 & 3.1 \\
\hline Staroshaigovsky & 18.0 & 23.2 & 46.9 & 11.9 & - \\
\hline
\end{tabular}

\section{Table 4}

\section{Phase compositions of carbonate rocks}

\begin{tabular}{|l|c|c|c|}
\hline \multirow{2}{*}{\multicolumn{1}{c|}{ Carbonate rock }} & \multicolumn{3}{|c|}{ Crystalline phases [wt. \%] } \\
\cline { 2 - 4 } & Calcite & Dolomite & Quartz modifications \\
\hline Yelnikovsky dolomite & 48 & 52 & 4 \\
\hline Atemarsky chalk & 96 & - & 4 \\
\hline
\end{tabular}


respectively. The phase composition of the Atermarsky chalk is represented predominantly by calcite $\mathrm{CaCO}_{3}(d=$ $[\ldots ; 3.87 ; \ldots ; 3.04 ; \ldots ; 2.50 ; \ldots ; 2.29 ; \ldots ; 2.10 ; \ldots ; 1.92 ; \ldots$; $1.88 \AA ; \ldots], 2 \theta=[\ldots ; 23.0 ; \ldots ; 29.3 ; \ldots ; 35.9 ; \ldots ; 39.3 ; \ldots$; $\left.\left.43.1 ; \ldots ; 47.4 ; \ldots ; 48.4^{\circ} ; \ldots\right]\right)$ with inclusions of quartz $\mathrm{SiO}_{2}$ $(d=[\ldots ; 4.31 ; \ldots ; 3.36 ; \ldots ; 1.82 \AA ; \ldots], 2 \theta=[\ldots ; 20.6 ; \ldots$; $\left.\left.26.5 ; \ldots ; 50.1^{\mathrm{o}} ; \ldots\right]\right)$ with the relative phase contents of 96 wt. $\%$ and 4 wt. $\%$, respectively (Table 4 ).

$\mathbf{a}$

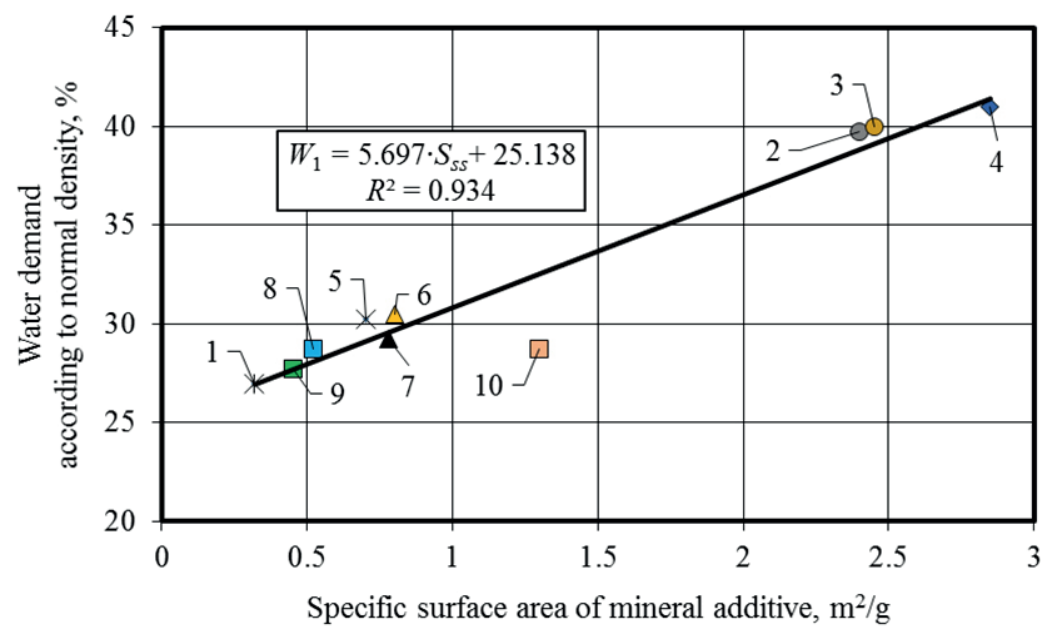

b

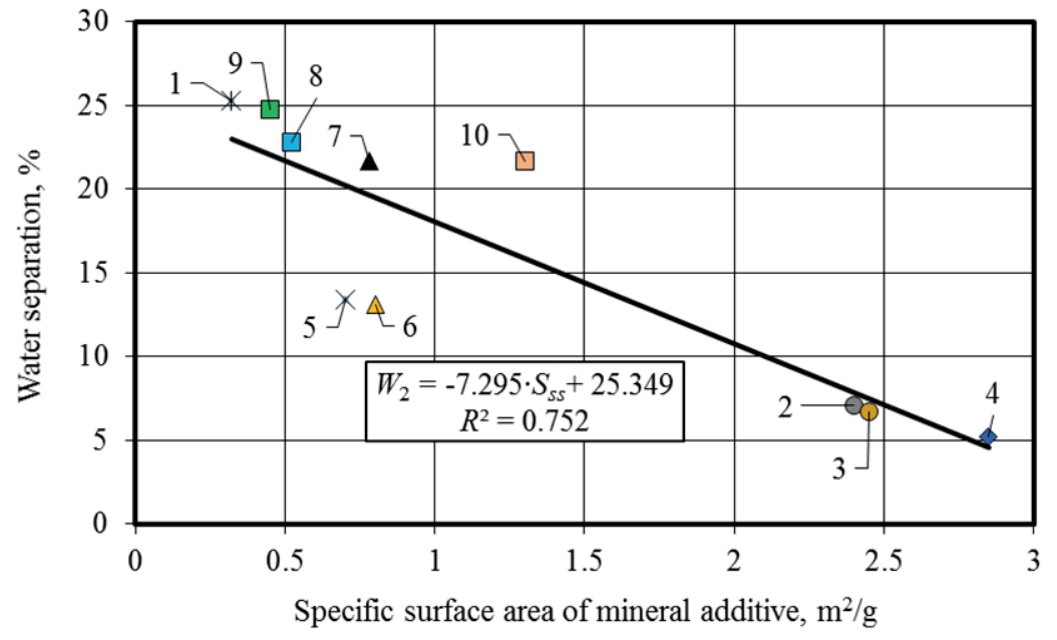

c

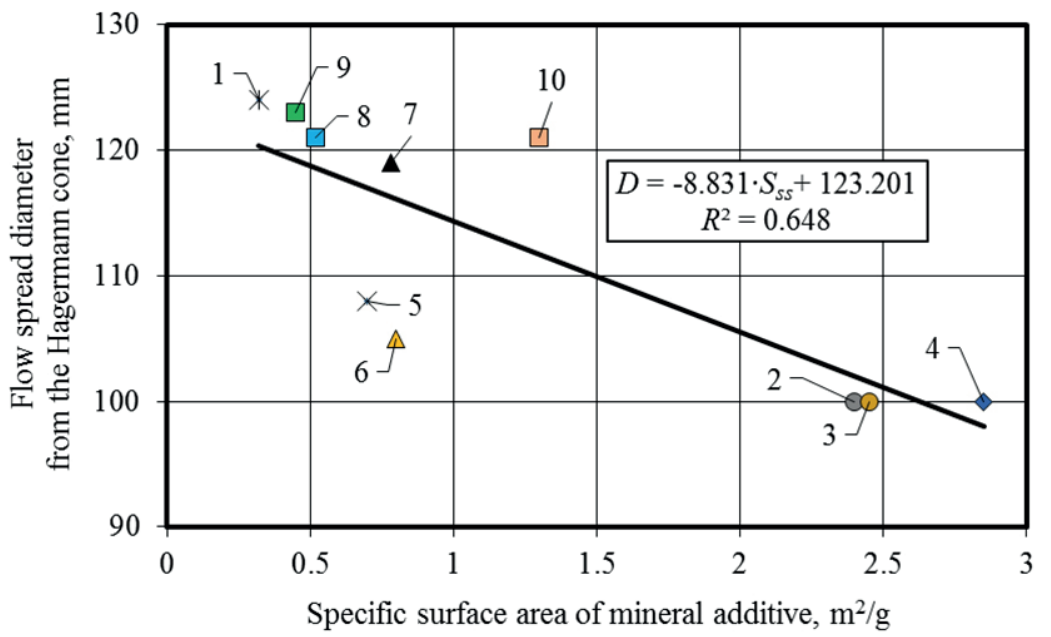

Fig. 2. Correlation dependences between the water demand according to normal density (a), water separation (b), flowability (c) of cement systems and the specific surface area of mineral additives 


\section{Influence of sedimentary rocks of different composition and genesis on the technological and physico-mechanical properties of cement systems}

Correlation dependences between the indicators of water demand ( $\left.W_{1}\right)$ (Fig. 2a), water-holding capacity $\left(W_{2}\right)$ (Fig. 2b), flowability (D) (Fig. 2c) of cement systems and the specific surface area of the applied mineral additives $\left(S_{\mathrm{ss}}\right)$ were established by the study results. In addition, dependence between the activity index of the studied modifiers $\left(C_{M A}\right)$ and the silicon dioxide content $\left(\omega_{\mathrm{SiO}_{2}}\right)$ in their composition was identified (Fig. 3). It should be noted that when establishing the last correlation dependence, only two compositions with siliceous rocks (No. 3 and 6, respectively) were included in the final selection.

From the analysis of obtained data (Fig. 2a), it was found that there is close enough correlation dependence $\left(R^{2}=0.934\right)$ between the water demand of cement binders according to normal density and the specific surface area of studied types of mineral additives introduced in an amount of $10 \%$ by the binder weight. Increase in the specific surface area of mineral additives leads to increase in the water demand of cement systems. At the same time, it was found that binders with the milled diatomite additives (compositions No. 2, 3 and 4) have the highest water demand indicator which is 1.5 times higher than the same indicator for Portland cement.

The binder water separation values (the water separation coefficient of cement paste by volume), on the contrary, decrease with increase in the specific surface area of mineral modifiers (Fig. 2b). The linear dependence between the specified indicator of cement systems and the specific surface area of MA studied types is characterized by sufficiently high coefficient of determination $\left(R^{2}\right)$ equal to 0.752 . Analyzing the results of experimental studies, it was found that Portland cement, carbonate rocks (DY and $\mathrm{CA}$ ) and calcined clay rocks (CCS and $\mathrm{CCN}$ ) have the lowest water-holding capacity from the investigated components of cement systems, as evidenced by the increased values of the water separation coefficient by cement paste volume in the compositions Nos. 1, 7, 8, 9, and 10 (25.3, 21.7, 22.8, 24.8, and 21.7\%, respectively (Fig. 2b)). The lowest water separation is observed in binders modified with MA based on diatomite (5.2-7.1\%, compositions Nos. 2, 3, and 4) and opoka (13.4 and 13.1\%, compositions Nos. 5 and 6 , respectively).

The cement system flowability, measured by flow spread diameter from Hagermann cone in the compositions with constant water content, also decreases with increasing specific surface areas of MA (Fig. 2c), while the coefficient of determination $\left(R^{2}\right)$ is equal to 0.648 . The study showed that the mineral additives used have thickening capacity which increases in sequence DY $\rightarrow$ CA and $\mathrm{CCS} \rightarrow \mathrm{CCN} \rightarrow \mathrm{OPK} 1 \rightarrow \mathrm{OPK} 2 \rightarrow \mathrm{DTMT} 1$, DTMT2, and DTMT3. The flow spread diameter of modified cement systems from the Hagermann cone is $100-123 \mathrm{~mm}$, which is up to $19 \%$ lower than that the composition without MA (124 mm).

The activity index of mineral additives is to some extent dependent on the silicon dioxide content in their compositions, which was established from the study results shown in Figure 3. Increase in the $\mathrm{SiO}_{2}$ concentration in the sedimentary rock composition contributes to increase in the modifier activity, as evidenced by the corresponding correlation dependence with $R^{2}$ equal to 0.461. It was found that the siliceous opal-cristobalite

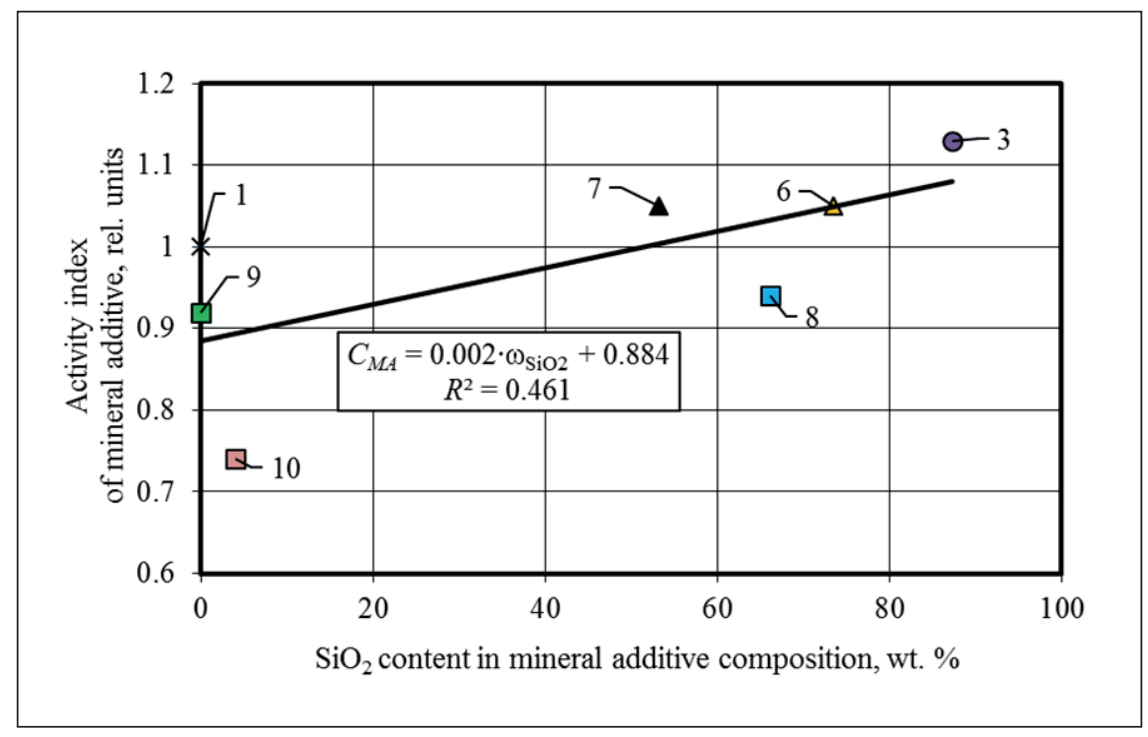

Fig. 3. Correlation dependence between the activity index of mineral additives and the silicon dioxide content in their compositions 
rocks (diatomite and opoka) are the most effective in cement systems, in particular, the activity indices of DTMT2 (composition No. 3) and OPK2 (composition No. 6) reach 1.13 and 1.05 rel. units, respectively. Mineral additives based on the calcined Nikitsky clay also have the chemical activity in cement systems, in particular, the CCN activity index in composition No. 7 was 1.05 rel. units.

\section{CONCLUSIONS}

The following results were obtained from experimental studies:

1) the chemical and mineralogical composition features were established for the initial siliceous rocks (diato- mite and opoka), polymineral clays and carbonate rocks (dolomite and chalk);

2) the effects of mineral additives based on sedimentary rocks of different composition on the water demand, water-holding capacity and flowability of the cement paste were revealed;

3 ) the influence of mineral modifiers on the mixed cement binder activity was established;

4) the most effective sedimentary rocks have been identified which make it possible to directionally control the technological and physical-mechanical properties of cement systems.

Atemarsky diatomite, Alekseevsky opoka and calcined Nikitsky clay were selected as the most promising types of mineral additives for further studies.

\section{REFERENCES}

1. Chernishov E.M., Artamonova O.V., Slavcheva G.S. Nanomodification of cement-based composites in the technological life cycle. Nanotechnologies in Construction. 2020; 12 (3): 130-139. https://doi.org/10.15828/2075-85452020-12-3-130-139.

2. Inozemtsev A.S., Korolev E.V. Comparative analysis of influence of nanomodification and micro-dispersed reinforcement on the process and parameters of destruction of high-strength lightweight concrete. Construction Materials. 2017; 7: 11-15.

3. Figovsky O.L., Beilin D.A. Ponomarev A.N. Successful implementation of nanotechnologies in building materials. Nanotechnologies in Construction. 2012; 3: 6-21.

4. Nizina T.A., Balykov A.S., Korovkin D.I., Volodin V.V. Physical and mechanical properties of modified finegrained fibre-reinforced concretes containing carbon nanostructures. International Journal of Nanotechnology. 2019; 16: 496-509. https://doi.org/10.1504/IJNT.2019.106621.

5. Ghafari E., Costa H., Júlio E., Portugal A., Durães L. The effect of nanosilica addition on flowability, strength and transport properties of ultra high performance concrete. Materials and Design. 2014; 59: 1-9. https://doi.org/10.1016/j. matdes.2014.02.051.

6. Jacob J.D.S., Mascelani A.G., Steinmetz R.L.R., Costa F.A.D., Dalla Costa O.A. Use of silica fume and nanosilica in mortars attacked by acids present in pig manure. Procedia Structural Integrity. 2018; 11: 44-51. https://doi. org/10.1016/j.prostr.2018.11.007.

7. Bazhenov Yu.M., Falikman V.R., Bulgakov B.I. Nanomaterials and Nanotechnologies in the Present-day Concrete Technology. Proceedings of Moscow State University of Civil Engineering. 2012; 12: 125-133.

8. Falikman V.R., Sobolev K.G. «There's plenty of room at the bottom», or how nanotechnologies can change the world of concrete. Part 1. Nanotechnologies in Construction. 2010; 2 (6): 17-31.

9. Rassokhin A.S., Ponomarev A.N., Figovsky O.L. Silica fumes of different types for high-performance fine-grained concrete. Magazine of Civil Engineering. 2018; 78: 151-160. https://doi.org/10.18720/MCE.78.12.

10. Chand G., Happy S.K., Ram S. Assessment of the properties of sustainable concrete produced from quaternary blend of portland cement, glass powder, metakaolin and silica fume. Cleaner Engineering and Technology. 2021; 4: 100179. https://doi.org/10.1016/j.clet.2021.100179.

11. Kocak Y. Effects of metakaolin on the hydration development of Portland-composite cement. Journal of Building Engineering. 2020; 31: 101419. https://doi.org/10.1016/j.jobe.2020.101419.

12. Mohammed A.M., Asaad D.S., Al-Hadithi A.I. Experimental and statistical evaluation of rheological properties of self-compacting concrete containing fly ash and ground granulated blast furnace slag. Journal of King Saud University - Engineering Sciences. 2021. https://doi.org/10.1016/j.jksues.2020.12.005.

13. Nedunuri S.S.S.A., Sertse S.G., Muhammad S. Microstructural study of Portland cement partially replaced with fly ash, ground granulated blast furnace slag and silica fume as determined by pozzolanic activity. Construction and Building Materials. 2020; 238: 117561. https://doi.org/10.1016/j.conbuildmat.2019.117561. 
14. Nizina T.A., Selyaev V.P., Balykov A.S., Volodin V.V., Korovkin D.I. Optimization of compositions of multicomponent fine-grained fiber concretes modified at different scale levels. Nanotechnologies in Construction. 2017; 9 (2): 43-65. https://doi.org/10.15828/2075-8545-2017-9-2-43-65.

15. Nizina T.A., Balykov A.S., Korovkin D.I., Volodin V.V. Modified fine-grained concretes based on highly filled self-compacting mixtures. IOP Conference Series: Materials Science and Engineering. 2019; 481: 012048. https://doi. org/10.1088/1757-899X/481/1/012048.

16. Mota dos Santos A.A., Cordeiro G.C. Investigation of particle characteristics and enhancing the pozzolanic activity of diatomite by grinding. Materials Chemistry and Physics. 2021; 270: 124799. https://doi.org/10.1016/j. matchemphys.2021.124799.

17. Taoukil D., El meski Y., Lahlaouti M.L., Djedjig R., El bouardi A. Effect of the use of diatomite as partial replacement of sand on thermal and mechanical properties of mortars. Journal of Building Engineering. 2021; 42: 103038. https://doi.org/10.1016/i.jobe.2021.103038.

18. Ahmadi Z., Esmaeili J., Kasaei J., Hajialioghli R. Properties of sustainable cement mortars containing high volume of raw diatomite. Sustainable Materials and Technologies. 2018; 16: 47-53. https://doi.org/10.1016/j.susmat.2018.05.001.

19. Sabir B.B., Wild S., Bai J. Metakaolin and calcined clays as pozzolans for concrete: a review. Cement and Concrete Composites. 2001; 23 (6): 441-454. https://doi.org/10.1016/S0958-9465(00)00092-5.

20. Gaifullin A.R., Rakhimov R.Z., Rakhimova N.R. The influence of clay additives in Portland cement on the compressive strength of the cement stone. Magazine of Civil Engineering. 2015; 59: 66-73. https://doi.org/10.5862/ MCE.59.7.

21. Balykov A.S., Nizina T.A., Volodin V.V., Kyashkin V.M. Effects of Calcination Temperature and Time on the Physical-Chemical Efficiency of Thermally Activated Clays in Cement Systems. Materials Science Forum. 2021; 1017: 61-70. https://doi.org/10.4028/www.scientific.net/MSF.1017.61.

22. Celik K., Hay R., Hargis C.W., Moon J. Effect of volcanic ash pozzolan or limestone replacement on hydration of Portland cement. Construction and Building Materials. 2019; 197: 803-812. https://doi.org/10.1016/j.conbuildmat.2018.11.193.

23. Lin R.-S., Wang X.-Y., Yi-Han. Effects of cement types and addition of quartz and limestone on the normal and carbonation curing of cement paste. Construction and Building Materials. 2021; 305: 124799. https://doi.org/10.1016/j. conbuildmat.2021.124799.

24. Lollini F., Redaelli E., Bertolini L. Effects of portland cement replacement with limestone on the properties of hardened concrete. Cement and Concrete Composites. 2014; 46: 32-40. https://doi.org/10.1016/j.cemconcomp.2013.10.016.

\section{INFORMATION ABOUT THE AUTHORS}

Artemy S. Balykov - Cand. Sci. (Eng.), Senior Researcher at the Research Laboratory of Ecological and Meteorological Monitoring, Building Technologies and Expertises, National Research Mordovia State University, Saransk, Russia, artbalrun@yandex.ru, https:// orcid.org/0000-0001-9087-1608

Tatyana A. Nizina - Dr. Sci. (Eng.), Professor, Professor at the Department of Building Constructions, National Research Mordovia State University, Saransk, Russia, nizinata@yandex.ru, https://orcid.org/0000-0002-2328-6238

Vladimir M. Kyashkin - Cand. Sci. (Phys.-Math.), Associate Professor, Associate Professor at the Department of Solid State Physics, National Research Mordovia State University, Saransk, Russia, kyashkin@mail.ru, https://orcid.org/0000-0002-3413-247X

Sergey V. Volodin - student, National Research Mordovia State University, Saransk, Russia, svolodin12@gmail.com, https://orcid. org/0000-0003-2018-4487

CONTRIBUTION OF THE AUTHORS

The authors contributed equally to this article.

\section{The authors declare no conflicts of interests.}

The article was submitted 10.01.2022; approved after reviewing 01.02.2022; accepted for publication 04.02.2022. 